\title{
Adsorptive removal of azo dyes from aqueous solutions by natural bentonite under static and dynamic flow conditions
}

\author{
A. Berez ${ }^{1,2} \cdot$ G. Schäfer $^{2}$ F. Ayari ${ }^{1}$ M. Trabelsi-Ayadi ${ }^{1}$
}

Received: 16 December 2015/Revised: 8 March 2016/Accepted: 13 April 2016/Published online: 3 May 2016

(C) Islamic Azad University (IAU) 2016

\begin{abstract}
This work reports new findings on the physisorption of Foron Blue 291 on natural bentonite under both static and dynamic flow conditions of the aqueous solution that may prove important when using the adsorption technique for wastewater treatment. The quantity of dye retained by the solid matrix under both ideal exchange conditions between dyes and adsorbents given in a batch reactor and a pulse injection of dissolved azo dye in a soil column composed of a mixture of mean grain-sized sand and bentonite at different flow rates and at various mass fractions of bentonite was studied. Column experiments involving the use of a non-reactive tracer (Fluorescein) were performed to examine hydrodynamic behaviours of the clay/sand mixture studied. It is shown that advective-dispersive transport across a clay/sand mixture may be characterized by a double porosity medium. The results obtained on the reactive transport of Foron Blue 291 underscore that Foron Blue 291 adsorption depends heavily on the mass fraction of clay in a clay/sand mixture. With a clay mass fraction of $30 \%, 77 \%$ of the dissolved Foron Blue 291 mass was irreversibly removed by the adsorbent. At low flow rates, removal ratios obtained from the dynamic reactive system were similar to those obtained through previous static reactor experiments.
\end{abstract}

G. Schäfer

schafer@unistra.fr

1 Laboratoire d'Application de la Chimie aux Ressources et Substances Naturelles et à l'Environnement (LACReSNE)UR 05- ES 09, Faculté des Sciences de Bizerte, Université de Carthage, 7021 Zarzouna, Bizerte, Tunisia

2 Laboratoire d'Hydrologie et de Géochimie de Strasbourg (LHyGeS) - UMR 7517 Centre National de Recherche Scientifique, Université de Strasbourg, 1 rue Blessig, 67084 Strasbourg Cedex, France
Keywords Sorption - Irreversibility · Bentonite - Azo dye · Batch $\cdot$ Column experiments $\cdot$ Wastewater treatment

\section{Introduction}

Colour effluents have appeared since the dyeing technique was first introduced. They are among the first contaminants to be found in wastewater. Various synthetic dyes have been detected in effluents originating from various industries (e.g. paper printing, dyeing, textiles, and colour photography) and are toxic and must be treated (Jiang et al. 2010). Over 10,000 different dyes and pigments are used in various industries worldwide. Global colour production levels are estimated to reach 800,000 tons/year, and at least $10 \%$ of dyes used are discharged into the environment (Palmieri et al. 2005). Even the presence of very low concentrations of these dyes generates coloured wastewater, which creates toxicological and technical problems relating to the reuse of water and which has serious environmental impacts when discharged into the hydrosystem.

In this study, we focus on Foron Blue 291(FB), an azo dye frequently used in the textile industry. This non-ionic dye is known to have carcinogenic, mutagenic and high colouring effects on the entire ecosystem when discharged as waste into the environment. It is highly stable and is resistant to degradation by chemical and biological processes. This dye is also considered a carcinogen or mutagen to humans. Therefore, the removal of dyes from wastewater is crucially important.

Dyes are conventionally removed from wastewater via a two-step treatment process that involves a physicochemical step that involves the addition of chemical reagents such as aluminium chloride and ferric chloride and a biological 
step that involves the use of activated sludge in adequately ventilated conditions (Edelin 1998). One difficulty encountered when using coagulation/flocculation agents during the physicochemical step occurs when particle flakes do not settle properly, rendering the system unable to remove dyes from water (El Kbir et al. 1998). Furthermore, biological processes are relatively less effective (Gerçel et al. 2008; Benguella and Yacouta-Nour 2009; Srinivasan and Viraraghavan 2010).

Other physicochemical techniques like sorption, electrochemical oxidation and photocatalytic degradation have been reported for the removal of dyes from wastewater. But among all, the adsorption technique was proven to be the most economical and efficient.

Various types of adsorbents were extensively used for elimination of dyes from aqueous solution: (1) biosorbents, e.g. algae, modified olive tree prunings (Calero et al. 2013) and activated carbons from apple pulp (Depci et al. 2012), (2) inorganic materials, e.g. natural zeolites (Calvo et al. 2009), bentonites (Berez et al. 2014), talcs (Young-Chul et al. 2015), phosphates (Barka et al. 2006) and (3) specifically developed adsorbent materials such as multiwalled carbon nanotubes (MWCNTs) (Zare et al. 2015; Rajabi et al. 2016; Sadegh et al. 2016), nanocomposites (Abdel Ghafar et al. 2015), nanoparticles (modified $\mathrm{TiO}_{2}$ ) (Yu et al. 2013), graphite surfaces (Shahryari-Ghoshekandi and Sadegh 2014), surface hydrogel polymers (Sadegh et al. 2015).

Adsorption techniques that involves the use of soil minerals as sorbents are promising due to their ease of operation, their comparably low application costs and the high water quality levels of treated effluents, especially when well-designed sorption processes are used (Eren and Afsin 2007; Qadeer 2007).

Typically, adsorption-desorption batch experiments are employed in laboratories to assess adsorption capacities of adsorbents while generating numerical data for the design of large-scale systems. However, batch reactors can be used to treat only small volumes of wastewater, and their uses in industrial applications are thus rather restricted. Alternatively, the use of continuous stirring tank reactors (CSTRs) can be considered a good alternative means for removing dissolved pollutants from water by adsorption (e.g. Mlayah and Jellali 2015). However, to separate solids charged with adsorbed pollutants from the liquid phase (e.g. water), one typically uses dynamic or fixed-bed adsorption systems for the remediation of polluted gases and liquids (Auta and Hameed 2014; Huan et al. 2016). These systems are designed in such a way that a dissolved pollutant continuously comes into direct contact with a fixed amount of adsorbent that successively removes the dissolved pollutant. In turn, large volumes of wastewater can be treated using less monitoring requirement. The system is simple to operate, is not very expensive and can easily be scaled up.

This paper reports new findings on the physisorption of FB on natural bentonite under both static and dynamic flow conditions of the aqueous solution that may prove important when employing adsorption techniques for wastewater treatment. Two major issues are studied: (1) the impact of dynamic mass transfer on the removal efficiency of clay minerals based on an examination of advective-dispersive mass transport with and without heterogeneous reactions that involve an adsorption-desorption process; (2) comparisons between quantities of dye retained by the solid matrix under both ideal exchange conditions among dyes and adsorbents in a batch reactor and the pulse injection of dissolved azo dye into a soil column. In the dynamic column experiments conducted, the fixed bed was composed of a mixture of mean grain-sized sand and bentonite at various mass fractions of bentonite. Different flow rates of injected dye solution are examined.

Batch experiments were first conducted to quantify the adsorption-desorption kinetics of $\mathrm{FB}$, the adsorption and desorption isotherms and labile and non-labile fractions of FB sorbed on bentonite. Then, controlled column experiments were performed to evaluate the influence of both the mass fraction of bentonite within the heterogeneous porous medium of sand and clay and the flow rate of dye solution on the amount of FB that can be adsorbed on natural bentonite and the proportion of FB that remains irreversibly attached to the solid matrix.

The experimental studies were carried out at Strasbourg University between 2013 and 2015 during the Ph.D. of Amor Berez.

\section{Materials and methods}

\section{Soil and dyes used}

Natural bentonite used in this study was obtained from deposits in Borj Chekir, Tunisia. The chemical composition of bentonite was determined by X-ray fluorescence spectroscopy and was found to be as follows: $53.34 \%$ $\mathrm{SiO}_{2}, 15.42 \% \mathrm{Al}_{2} \mathrm{O}_{3}, 8.21 \% \mathrm{Fe}_{2} \mathrm{O}_{3}, 4.75 \% \mathrm{MgO}, 1.32 \%$ $\mathrm{K}_{2} \mathrm{O}, 4.61 \% \mathrm{CaO}, 0.75 \% \mathrm{Na}_{2} \mathrm{O}$ and $11.60 \%$ other (Berez 2015). The mineralogical analysis results show that the raw clay mineral is an interstratified smectite-kaolinite that contains preponderantly montmorillonite; the clay composition also includes some impurities such as quartz and calcite. Its specific surface area (SSA) of $383 \mathrm{~m}^{2} \mathrm{~g}^{-1}$ was determined via the methylene blue method (Ghorbel-Abid and Trabelsi-Ayadi 2011) using a Shimatzu UV-1700 spectrophotometer. 
In our dynamic flow experiments, the experimental setup was filled with a mixture of bentonite and mediumgrained sand. The sand sample has a low fraction of organic matter (foc $=0.09 \%$, based on the French standard NF X 31-109) and a hydraulic conductivity of approximately $8 \times 10^{-4} \mathrm{~m} \mathrm{~s}^{-1}$. The sand has already been the subject of several former research studies, and its characteristics were described by Jellali et al. (2003), Benremita (2002), Bohy (2003), Bohy et al. (2006), and Cotel et al. (2011). The measured equivalent hydraulic conductivity of the clay/sand mixture was approximately $2 \times 10^{-4}, 5 \times 10^{-6}$ and $7 \times 10^{-7} \mathrm{~m} \mathrm{~s}^{-1}$ for a mass fraction of clay of 10,20 , and $30 \%$, respectively.

In the column experiments, two types of dye were used: (1) a reactive dye and (2) a conservative dye. FB dye was used in all our experimental studies as a reactive species. This dye is referred to as "dark blue", is widely used in the textile industry for the production of cotton clothes and is frequently used for the production of wool and polyester materials (Sørensen 1996). FB is a chemically neutral molecule with a molar mass of $509.3 \mathrm{~g} \mathrm{~mol}^{-1}$ and with $\mathrm{C}_{19} \mathrm{H}_{21} \mathrm{BrN}_{6} \mathrm{O}_{6}$ as its formula (Fig. 1).

Fluorescein $\left(\mathrm{C}_{20} \mathrm{H}_{10} \mathrm{Na}_{2} \mathrm{O}_{5}\right.$ or $3 \mathrm{H}$-xanthene-3-one $)$ (Fig. 1) is a fluorescent tracer that is frequently used in hydrological studies to record the movement of water molecules in rivers and groundwater. In our column experiments, it was used as a reference to characterize the advective-dispersive transport of a non-reactive solute through a porous medium. Fluorescein, which is often referred to as uranine, is a chemical complex composed of two phenol molecules linked to a pyran ring that is connected to a benzoic acid. This substance is fluorescent green in colour when reflected by daylight and emits reflected light with a wavelength of $532 \mathrm{~nm}$ when excited by incident light with a wavelength of $488 \mathrm{~nm}$.

\section{Batch reactor}

The adsorption of FB on raw bentonite samples was studied at room temperature $\left(22 \pm 2{ }^{\circ} \mathrm{C}\right)$ using classical batch reactors. One gram of raw solid was added to $100 \mathrm{~mL}$ of the dye water solutions at the desired FB concentrations, which varied from 20 to $140 \mathrm{mg} \mathrm{L}^{-1}$. Next, the mixture $(\mathrm{pH}$ 6.5) was shaken over a specified period. The maximum contact time between the adsorbent and dye solution was $2 \mathrm{~h}$. This time was chosen because no additional significant variations were found in the dye concentration in correspondence with the equilibrium state of mass transfer. In addition, the specified period was chosen based on the results of a previous study on adsorption kinetics.

Once the thermodynamic equilibrium state was achieved, the samples were clarified by centrifuging at $3500 \mathrm{rpm}$. The FB concentration was determined via UV spectrophotometry at a maximum wavelength $\lambda_{\max }$ of $579 \mathrm{~nm}$ (Shimatzu Corporation, UV-1700). Kinetic adsorption studies were conducted at one initial FB concentration. In these experiments, the quantity of adsorbed FB was measured over time.

Six desorption experiments were conducted at fixed FB concentrations that were initially adsorbed on the raw bentonite sample: 0.65 (Run 6), 1.37 (Run 5), 1.87 (Run 4), 2.32 (Run 3), 2.75 (Run 2) and $3.11 \mathrm{mg} \mathrm{g}^{-1}$ (Run 1). The suspension was agitated for $2 \mathrm{~h}$ prior to centrifuging and analysing as described in reference to the adsorption experiments. Next, $20 \mathrm{~mL}$ of demineralized water was added to the bentonite samples following the removal of $20 \mathrm{~mL}$ of the supernatant solution during the adsorption step. This process was repeated eight times for the raw bentonite samples under each concentration setting.

In addition, a kinetic desorption study was conducted by initially fixing $3.8 \mathrm{mg}$ of FB mass on $1 \mathrm{~g}$ of the raw bentonite sample and by examining the mass of FB released into the aqueous solution over time.

\section{Laboratory column}

Adsorption-desorption experiments on azo dye on bentonite under dynamic flow conditions were performed on columns (length $L=36 \mathrm{~cm}$, inner diameter $D=3.9 \mathrm{~cm}$ )
Fig. 1 Chemical structure of a Foron Blue 291 and b Fluorescein

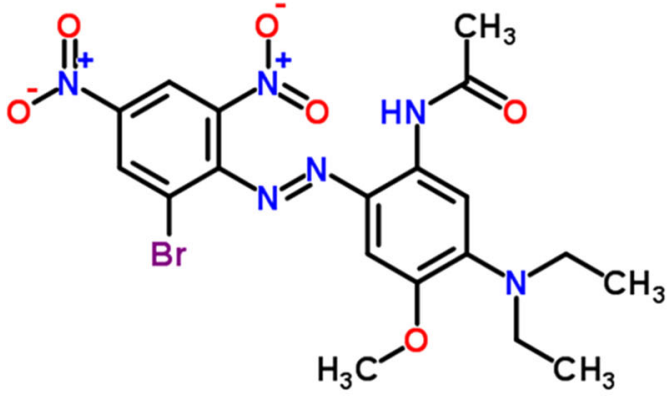

(a)<smiles></smiles>

(b) 
composed of glass filled with water-saturated sand and a mixture of sand/bentonite. The characteristics of the experimental setup are described in Fig. 2. The column was filled with a 20 -cm-thick layer of medium grain-sized sand, an 11-cm-thick layer of a mixture of medium grainsized sand and bentonite and a 5-cm-thick layer of medium grain-sized sand.

The flow mode selected was oriented downward. During the experiments, a constant flow rate of water was applied to the water-saturated soil column inlet using a peristaltic pump combined with pulse injections of either tracer (fluorescein) or FB at fixed concentrations of 9 or $50 \mathrm{mg} \mathrm{L}^{-1}$, respectively. A fixed water head was prescribed at the downstream tank. The inlet chamber of the column was equipped with a valve and flushing port that forced solute mixing in the inlet chamber. Via suitable valve and flushing port operation, we ensured that the solutes (tracer or FB) were introduced uniformly over the column entrance cross section.

In all the transport experiments, the injection volume of the tracer and FB pulse was equal to $1200 \mathrm{~mL}$ of tracer and FB, respectively. This corresponded with the studied flow rates, which varied between 2 and $20 \mathrm{~mL} \mathrm{~min}^{-1}$ over pulse injection periods of 600 and $60 \mathrm{~min}$. The experiments were conducted at a constant temperature of $22^{\circ} \mathrm{C}$. Tracer concentrations were automatically measured every $10 \mathrm{~s}$ at the light fibre fluorometer probe introduced into the tube close to the column outlet using a portable fluorometer device. During the reactive transport experiments, water samples were manually collected at defined time intervals at the three-way sampling valve close to the column outlet
(Fig. 2) and were analysed via UV spectrophotometry at a maximum wavelength $\lambda_{\max }$ of $579 \mathrm{~nm}$ to determine FB breakthrough patterns.

Two series of reactive transport experiments were performed. The column and fluid injection filling procedures were identical. The first series of experiments focused on the study of percentages of clay in the sand/clay mixture upon the removal of azo dye from water at a fixed flow rate of $10 \mathrm{~mL} \mathrm{~min}{ }^{-1}$. Three mixtures were studied: $10 \%$ clay/ $90 \%$ sand, $20 \%$ clay/80\% sand and $30 \%$ clay $/ 70 \%$ sand.

The second series of experiments focused on examining variations in the flow rates of fluids passing through the porous medium while keeping the $20 \%$ percentage of clay constant in the sand/clay layer. Six different flow rates were studied in the following descending order: $20,15,10$, 7, 5 and $2 \mathrm{~mL} \min ^{-1}$.

\section{Mathematical models}

\section{Adsorption and desorption kinetics}

The time-dependant concentration of the aqueous dye solution $c_{\mathrm{t}}$ was calculated as follows using Eq. (1):

$c_{t}=\frac{D O_{t}-d}{c}$,

where $c$ is the slope of the calibration curve of the optical density $\left(\mathrm{DO}_{t}\right)$ as a function of $c_{t}$ and $d$ is the intercept.

The amount of dye per gram of adsorbent at time $t$ was calculated as follows:
Fig. 2 Scheme of the experimental setup

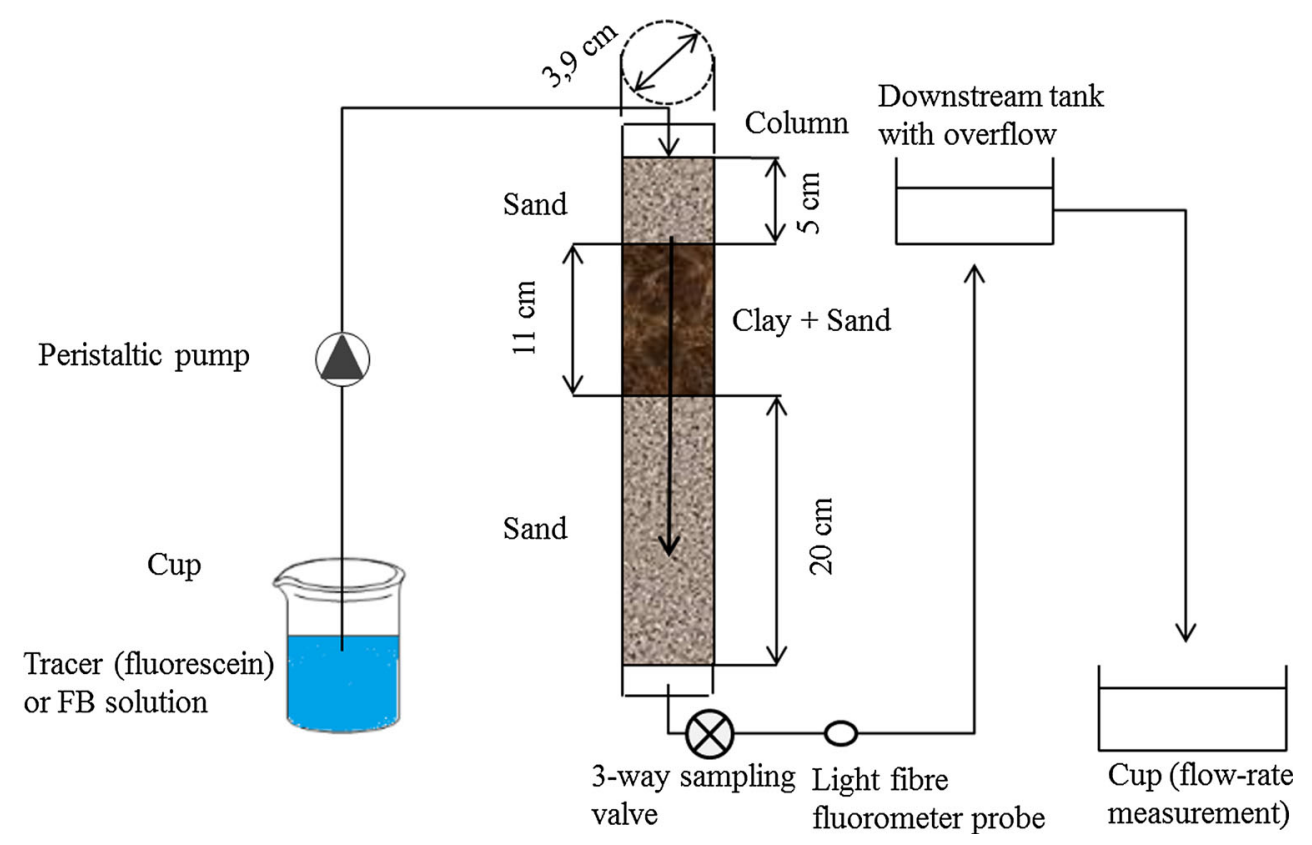


$q_{t}^{(n)}=\frac{V}{m}\left(c_{i}-c_{t}^{(n)}+(r-1) \sum_{i=0}^{n-1} c_{t}^{(i)}\right)$,

where $q_{t}\left[\mathrm{mg} \mathrm{g}^{-1}\right]$ corresponds to the fixed quantity of dye on the adsorbent at time $t ; c_{\mathrm{i}}\left[\mathrm{mg} \mathrm{L}^{-1}\right]$ and $c_{\mathrm{t}}^{(n)}\left[\mathrm{mg} \mathrm{L}^{-1}\right]$ are the initial aqueous solution dye concentration and the supernatant dye concentration after the desorption step $(n)$, respectively; $V[\mathrm{~L}]$ is the solution volume; $m[\mathrm{~g}]$ is the mass of the adsorbent used; and $r$ is the ratio of the volume of the supernatant remaining in the slurry during the desorption step to the initial volume. In addition, $n$ is the number of desorption steps, $(n>0)$ and $i=0$ and $n=0$ correspond to the precedent adsorption step. For our study on adsorption and desorption kinetics, we used the quasi-linearized solution of the pseudo-first-order model (Table 1).

For the model on pseudo-first-order adsorption kinetics, the maximum amount of FB adsorbed $\left(q_{e}\right)$ and the rate constant of adsorption $\left(k_{1}\right)$ were quantified using the quasilinearized solution (Eq. (5)) (see Table 1) coupled with an iterative Picard scheme and a linear regression of Eq. 5 based on the least-mean-square method (see the following section). At the final iterative step, $q_{e}$ was obtained from the intercept of the straight line, whereas $k_{1}$ was obtained from the slope of the straight line. The same numerical procedure was employed for the model on pseudo-first-order desorption kinetics (Eq. 7) to quantify the irreversible final amount of FB adsorbed $\left(q_{e}\right)$ and the rate constant of desorption $k_{1}$ based on the initially adsorbed amount of FB $\left(q_{e}^{0}\right)$.

\section{Adsorption isotherm}

To model the adsorption isotherms of the azo dye on the bentonite sample, we used Langmuir's traditional two-

Table 1 Equations used for the study on adsorption and desorption kinetics

\begin{tabular}{|c|c|c|}
\hline $\begin{array}{l}\text { Ordinary } \\
\text { differential } \\
\text { equation }\end{array}$ & $\begin{array}{l}\frac{\mathrm{d} q_{t}}{\mathrm{~d} t}=k_{1}\left(q_{e}-q_{t}\right) \\
\mathrm{q}_{\mathrm{e}}\left[\mathrm{mg} \mathrm{g}^{-1}\right] \text { is the adsorbed dye } \\
\text { concentration at equilibrium and } \mathrm{k}_{1} \\
{\left[\mathrm{~min}^{-1}\right] \text { is the kinetic constant of }} \\
\text { adsorption or desorption }\end{array}$ & (3) \\
\hline \multicolumn{3}{|l|}{ Adsorption kinetic } \\
\hline Initial conditions & at $t=0 q_{\mathrm{t}}=0$ & \\
\hline $\begin{array}{l}\text { Solution of } \\
\text { Eq. (3) }\end{array}$ & $q_{t}=q_{e}\left(1-e^{-k_{1} t}\right)$ & (4) \\
\hline $\begin{array}{l}\text { Quasi-linearized } \\
\text { solution }\end{array}$ & $\log \left(q_{e}-q_{t}\right)=\log \left(q_{e}\right)-\frac{k_{1}}{2,3} t$ & (5) \\
\hline \multicolumn{3}{|l|}{ Desorption kinetic } \\
\hline Initial conditions & at $t=0 q_{\mathrm{t}}=q_{\mathrm{e}}^{0}$ & \\
\hline $\begin{array}{l}\text { Solution of } \\
\text { Eq. (3) }\end{array}$ & $q_{t}=q_{e}\left(1-e^{-k_{1} t}\right)+q_{e}^{0} e^{-k_{1} t}$ & (6) \\
\hline $\begin{array}{l}\text { Quasi-linearized } \\
\text { solution }\end{array}$ & $\log \left(q_{e}-q_{t}\right)=\log \left(q_{e}-q_{e}^{0}\right)-\frac{k_{1}}{2,3} t$ & (7) \\
\hline
\end{tabular}

parameter model (Langmuir 1916, 1918), which accurately represents the observed L-form adsorption isotherm (Berez 2015). The Langmuir equation can be written as follows:

$q_{e}=\frac{q_{m} b c_{e}}{1+b c_{e}}$,

where $q_{\mathrm{e}}\left[\mathrm{mg} \mathrm{g}^{-1}\right]$ and $c_{\mathrm{e}}\left[\mathrm{mg} \mathrm{L}^{-1}\right]$ are the quantity of FB adsorbed and the dye concentration in the liquid, respectively; $q_{\mathrm{m}}\left[\mathrm{mg} \mathrm{g}^{-1}\right]$ represents the adsorption capacity at saturation (characterizing the formation of a single layer of adsorbed molecules); and $b\left[\mathrm{~L} \mathrm{mg}^{-1}\right]$ is the equilibrium constant of the adsorbent. $q_{\mathrm{m}}$ and $b$ depend on temperature and operating conditions. Equation (8) can be rewritten in its linearized form to successfully determine the $q_{\mathrm{m}}$ and $b$ parameters as follows:

$\frac{1}{q_{e}}=\frac{1}{q_{m} b c_{e}}+\frac{1}{q_{m}}$

Based on a linear regression of Eq. 9 involving the use of the least-mean-square method (see the following section), we obtained $q_{\mathrm{m}}$ from the intercept and $b$ from the slope of the straight line.

\section{Least-mean-square method and error quantification}

In our study, parameters of the equations used to describe the kinetics of FB adsorption and desorption on the bentonite sample and the adsorption isotherm of FB were determined using the least-mean-square method (LMSM).

Let us consider a scatterplot $M_{\mathrm{i}}\left(X_{\mathrm{i}}, Y_{\mathrm{i}}\right)$ and a linear function $f(X)$ of the following form

$f \rightarrow Y=a X+b$

where $a$ and $b$ are the slope and intercept of the straight line, respectively. The best fit of the scatterplot based on $f$ is determined by varying $a$ and $b$ in a way that minimizes the sum of squared distances between $Y_{\mathrm{i}}$ and $f\left(X_{\mathrm{i}}\right)$, which is defined as follows

$D=\sum_{1}^{n}\left[Y_{i}-f\left(X_{i}\right)\right]^{2}$

where $n$ is the number of available data points. The best fit of $a$ and $b$ is obtained when the partial derivatives of $D$ with respect to $a$ and $b$ become zero

$\frac{\partial D(a, b)}{\partial a}=\frac{\partial D(a, b)}{\partial b}=0$

Solving the system of Eq. (12) results in

$$
\begin{aligned}
& a=\frac{n \sum X_{i} Y_{i}-\sum X_{i} \sum Y_{i}}{n \sum X_{i}^{2}-\left(\sum X_{i}\right)^{2}} \\
& b=\frac{\sum Y_{i} \sum X_{i}^{2}-\sum X_{i} Y_{i} \sum X_{i}}{n \sum X_{i}^{2}-\left(\sum X_{i}\right)^{2}}
\end{aligned}
$$


Uncertainties with respect to $a$ and $b$ can be further quantified using (Dodge and Rousson 2004):

$\Delta a=\sigma \sqrt{\frac{n}{n \sum X_{i}^{2}-\left(\sum X_{i}\right)^{2}}}$

$\Delta b=\sigma \sqrt{\frac{\sum X_{i}^{2}}{n \sum X_{i}^{2}-\left(\sum X_{i}\right)^{2}}}$

with $\sigma=\sqrt{\frac{\sum \varepsilon_{i}^{2}}{n-2}}$ and $\varepsilon_{i}=Y_{i}-\left(a X_{i}+b\right)$

To determine how well the experimental data points fit adsorption/desorption kinetics or the isotherm adsorption model described in the previous section, we used the root-mean-square error (RMSE) defined as follows:

$\operatorname{RMSE}=\sqrt{\frac{1}{n} \sum_{i=1}^{n}\left(\left(q_{\mathrm{i}, \mathrm{cal}}-q_{\mathrm{i}, \exp }\right) / q_{\mathrm{i}, \exp }\right)^{2}}$,

where $q_{\mathrm{i} \text {,cal }}\left[\mathrm{mg} \mathrm{g}^{-1}\right]$ is the calculated amount of dye that was adsorbed via adsorption/desorption kinetics or using the isotherm adsorption models and $q_{\mathrm{i} \text { exp }}\left[\mathrm{mg} \mathrm{g}^{-1}\right]$ is the experimentally measured amount of dye adsorbed.

\section{Analysis of breakthrough curves}

Breakthrough curves of fluorescein and FB measured at the column outlet were analysed using the method of moments to calculate the mass recovery of the injected dye solution, the effective porosity level and the retardation factor of the sand/clay mixture.

The $n$-th temporal moment of the concentration distribution $c(x, t)$, where $x$ is the coordinate of observation and $\mathrm{t}$ is the starting time from $t=0$, is defined as follows (Aris 1958)

$M_{n, t}=\int_{0}^{\infty} t^{n} c(x, t) \mathrm{d} t$

Normalized temporal moments of the $n$-th order are then obtained from

$m_{n, t}=M_{n, t} / M_{0, t}$

In this study, the zeroth temporal moment was calculated by determining the total mass of species eluted from the column and was then normalized to the injected known mass to obtain the mass removal ratio in both the sand filling and the sand/clay mixture.

Mass removal ratio $=1-\frac{M_{0, t}}{c_{0} \Delta t}$

where $c_{0}\left(\mathrm{mg} \mathrm{L}^{-1}\right)$ is the constant concentration of the nonreactive tracer (fluorescein) or FB under the injection pulse width condition $\Delta t(s)$.
Note that mass eluted from the column $m_{e}(\mathrm{mg})$ was quantified using Eq. (18), where the zeroth moment was approximated from the integral of concentration between data limits $A$ and $B$ using the rectangular rule

$m_{e}=Q M_{0, t} \approx Q \int_{A}^{B} c(x, t) \mathrm{d} t \approx Q \sum_{A}^{B} c_{i}(x, t) \Delta t_{i}$

where $Q$ is the flowrate of water applied to the soil column.

The mean travel time of the species in the soil column of length $L$ was determined by subtracting one half of the injection pulse width $(\Delta t)$ from the first normalized temporal moment (Schäfer 1991):

$\tau \equiv \frac{L}{v_{\mathrm{m}}}=m_{1, t}-\frac{\Delta t}{2}$

where $v_{\mathrm{m}}\left(\mathrm{ms}^{-1}\right)$ is the mean pore velocity in the porous medium. Note that in the three-layered column filling, the mean travel time obtained from Eq. (22) is the sum of three individual travel times resulting from the three-layered structure of the column filling (see Fig. 2). Based on the quantified mean pore velocity, the effective porosity $n_{e}$ of both the column filling and the porous medium (sand and sand/clay mixture) are then obtained from:

$n_{e} \equiv \frac{v_{\mathrm{D}}}{v_{\mathrm{m}}}$

where $v_{\mathrm{D}}\left(\mathrm{ms}^{-1}\right)$ is the specific discharge or Darcy velocity. Note that under steady-state flow conditions, $v_{\mathrm{D}}$ is strictly constant along the soil column, whereas $v_{\mathrm{m}}$ will vary in the three-layered structure of the column filling.

The ratio of the travel time required for FB to cross the 36-cm-long soil column to that of the non-reactive tracer (fluorescein) was used to determine the retardation factor of FB.

In the case of the advective-dispersive transport of a non-reactive tracer in a homogeneous porous medium of length $\mathrm{L}$, the longitudinal dispersion coefficient $D_{L}\left(\mathrm{~m}^{2} \mathrm{~s}^{-1}\right)$ is obtained from the second normalized moment (Schäfer 1991):

$D_{L}=\left(m_{2, t}-\left[\frac{1}{3} \Delta t^{2}+\frac{L}{v_{m}} \Delta t+\frac{L^{2}}{v_{m}^{2}}\right]\right) \frac{v_{m}^{3}}{2 L}$

In the case of large Péclet numbers $\left(\mathrm{Pe}=v_{\mathrm{m}} d_{50} / D_{0}>10\right.$; where $d_{50}(-)$ and $D_{0}\left(\mathrm{~m}^{2} \mathrm{~s}^{-1}\right)$ are the mean grain size diameter and the coefficient of molecular diffusion in water, respectively), the longitudinal dispersivity of the porous medium can then be evaluated from

$\alpha \approx \frac{D_{L}}{v_{\mathrm{m}}}$

Equations 24 and 25 are used to determine the longitudinal dispersivity of the sand filling. When applied to the three-layered column filling, the longitudinal 
dispersivities represent average values of an equivalent homogeneous porous medium.

\section{Results and discussion}

\section{Batch experiments}

\section{Kinetics of dye adsorption and desorption}

Figure 3 shows variations identified in the measured and modelled FB dyes that were adsorbed into the natural solid material over time. The observed dye adsorption kinetics were characterized by the strong adsorption of the dye into the sample during the first few minutes of dye-bentonite contact. Next, dye adsorption levels slowly increased until a steady state of mass transfer equilibrium was achieved after approximately $100 \mathrm{~min}$.

The mass transfer of the dye from a liquid to a solid phase over the first few minutes of the reaction was fast. This rapid process of mass transfer may have occurred because the number of available active sites on the surface of the adsorbent material is more important at the start of the adsorption process than the active sites remaining after one-tenth of the time has passed (Yaneva and Koumanova

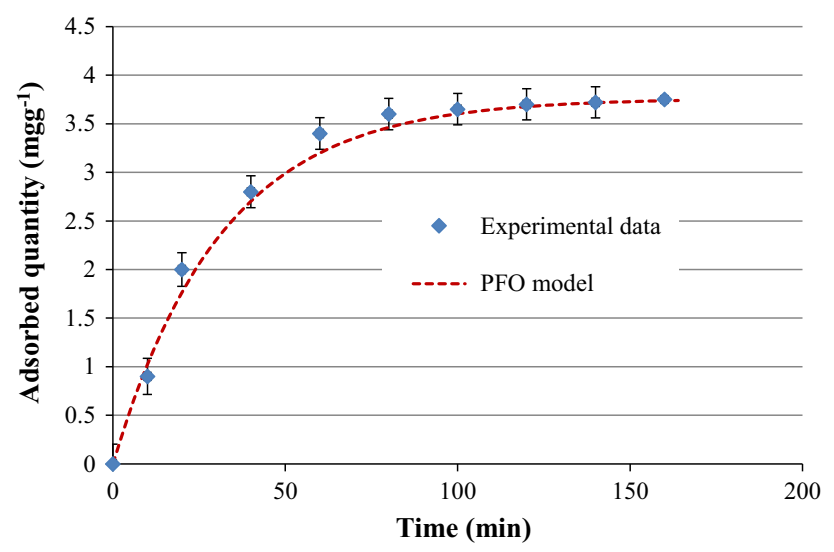

Fig. 3 Kinetics of FB adsorption on the bentonite sample from Borj Chekir. The experimental data were fitted according to the pseudofirst-order (PFO) model based on Eq. 4
2006; Dincer et al. 2007; Berez et al. 2014; Sadegh et al. 2015; Zare et al. 2015).

The modelled adsorption kinetics shown in Fig. 3 are based on kinetic parameters (Table 2) that were determined from a linear regression of the quasi-linear solution (Eq. 5). The model parameters of the pseudo-first-order (PFO) equations presented in the literature vary considerably depending on the nature of the adsorbate and adsorbent. Indeed, an adsorbate can be a metal, a gas or an organic compound (e.g. dyes), and an adsorbent can be a material residue (e.g. a bioadsorbent or algae) or a material (e.g. talc phosphate or bentonite). For example, Wang et al. (2013) identified a PFO rate constant of $2 \times 10^{-2} \mathrm{~min}^{-1}$, which is approximately 1.5 times smaller than the rate constant observed in our study. However, the adsorbed concentration observed by Wang et al. (2013) was approximately $123 \mathrm{mg} \mathrm{g}^{-1}$, which differs considerably from our results. These high quantities can be explained by the nature of the cationic dye used (methylene blue), which presents higher adsorption affinities for bentonite than non-ionic and anionic dyes. As bentonites are negatively charged, attractive forces are generally found between bentonites and positively charged dyes.

Based on an initially adsorbed amount of $3.8 \mathrm{mg} \mathrm{g}^{-1}$ $\mathrm{FB}$, desorption kinetics of $\mathrm{FB}$ on the bentonite sample are presented in Fig. 4. A portion of the initially fixed dye concentration is rapidly released. However, the desorption process slows down significantly after approximately $60 \mathrm{~min}$ and reaches a plateau after approximately $80 \mathrm{~min}$. After $80 \mathrm{~min}$, fixed dye concentrations remain nearly unchanged, which can be explained by the complete cessation of dye desorption or by the occurrence of an equilibrium state between adsorption and desorption. However, the time required to achieve this state was shorter than the time required for the adsorption of $\mathrm{FB}$ on the raw bentonite (see Fig. 3). This decrease in the mass of the dye retained on the bentonite sample per the mass of the solids can be adequately described based on pseudo-first-order model. The quantified desorption rate constant is thus higher than the rate constant of the adsorption process (Table 2). The desorption kinetics of dyes from bentonite minerals have rarely been discussed in the literature. The rate constants obtained for adsorption and desorption kinetics are similar

Table 2 Model parameters determined for (a) the kinetics of sorption using a pseudo-first-order model and (b) Langmuir isotherms of FB adsorption

\begin{tabular}{llcc}
\hline (a) Kinetics of sorption & $\mathrm{q}_{\mathrm{e}}\left(\mathrm{mg} \mathrm{g}^{-1}\right)$ & $\mathrm{k}_{1}\left(\mathrm{~min}^{-1}\right)$ & $\mathrm{RMSE}(-)$ \\
\hline Adsorption & $3.77 \pm 0.034$ & $0.031 \pm 1.5 \times 10^{-3}$ & 0.065 \\
Desorption & $2.47 \pm 0.02$ & $0.049 \pm 1.7 \times 10^{-3}$ & 0.013 \\
\hline (b) Adsorption isotherm & $\mathrm{b}\left(\mathrm{L} \mathrm{mg} \mathrm{m}^{-1}\right)$ & $\mathrm{q}_{\mathrm{m}}\left(\mathrm{mg} \mathrm{g}^{-1}\right)$ & $\mathrm{RMSE}(-)$ \\
\hline & $0.066 \pm 0.023$ & $4.54 \pm 0.82$ & 0.036 \\
\hline
\end{tabular}




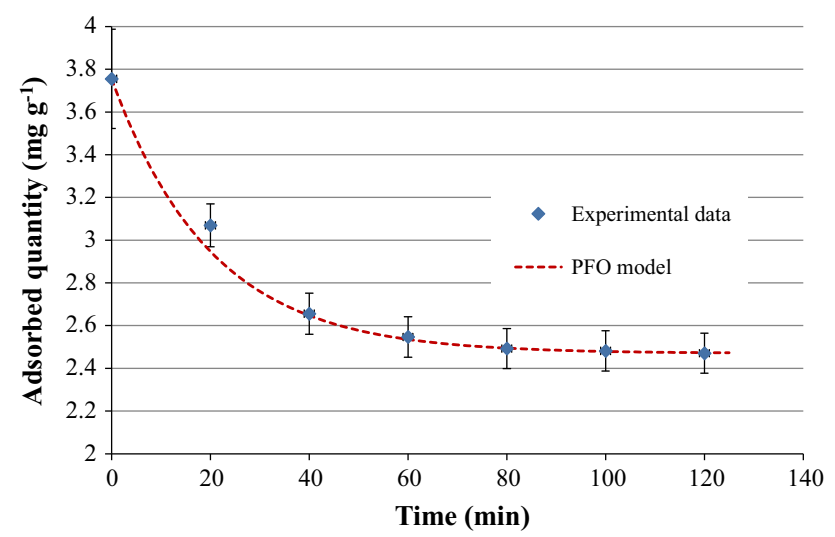

Fig. 4 Kinetics of FB desorption on the bentonite sample from Borj Chekir. The experimental data were fitted according to the pseudofirst-order (PFO) model based on Eq. 6

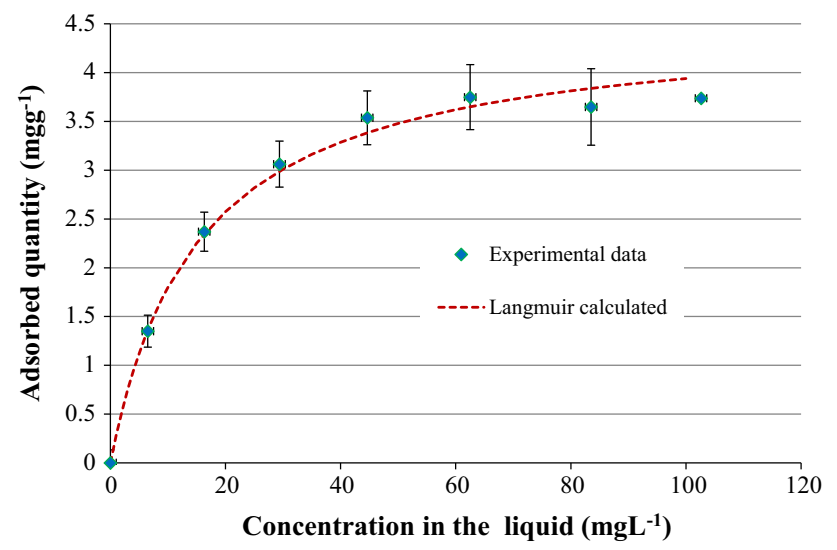

Fig. 5 Adsorption isotherm of the FB dye on the bentonite sample from Borj Chekir and modelling results obtained from the Langmuir adsorption model to those obtained by Berez et al. (2014) for FB on raw bentonite extracted from Jebel Stah deposits (Gafsa) in the western region of Tunisia.

\section{Adsorption and desorption isotherms}

Figure 5 shows the results of the batch experiments relative to the modelling results that were obtained from the Langmuir adsorption model. As shown in Fig. 5, the amount of adsorbed dye increases rapidly at low concentrations and reaches a plateau at a high concentration of approximately $60 \mathrm{mg} \mathrm{L}^{-1}$ that corresponds with the saturation of the adsorption sites.

In this study, the model parameters of the Langmuir isotherm (Table 2) were similar to those provided in the literature. However, the model parameters strongly depend on the products involved. For example, Berez et al. (2014) found $\mathrm{b}$ and $q_{\mathrm{m}}$ values of $0.081 \mathrm{~L} \mathrm{mg}^{-1}$ and $4.58 \mathrm{mg} \mathrm{g}^{-1}$, respectively, when studying the adsorption of a bentonite extracted from a Jebel Stah deposit (Gafsa) containing a high fraction of smectite of approximately $80 \%$. This shows that both bentonites present the same sorption behaviours relative to FB even when mineralogical compositions differ considerably.

Figure 6 shows the measured isotherms of FB desorption from the natural bentonite. The experimental results are represented by symbols. In addition, each desorption experiment was modelled separately. The shapes of the trend cures were modelled using second-order polynomials for initially adsorbed dye masses of $3.11,2.75,2.32,1.87$, 1.37 and $0.65 \mathrm{mg} \mathrm{g}^{-1}$ (Table 3). The measured desorption isotherms are different from the given adsorption isotherm and heavily depend on the initial dye mass that was adsorbed on the bentonite sample (Fig. 7). The desorption
Fig. 6 FB dye mass retained on the bentonite sample during isothermal desorption as a function of dye concentrations in the aqueous solution $\left(c_{e}\right)$ and the modelled trend curves of desorption

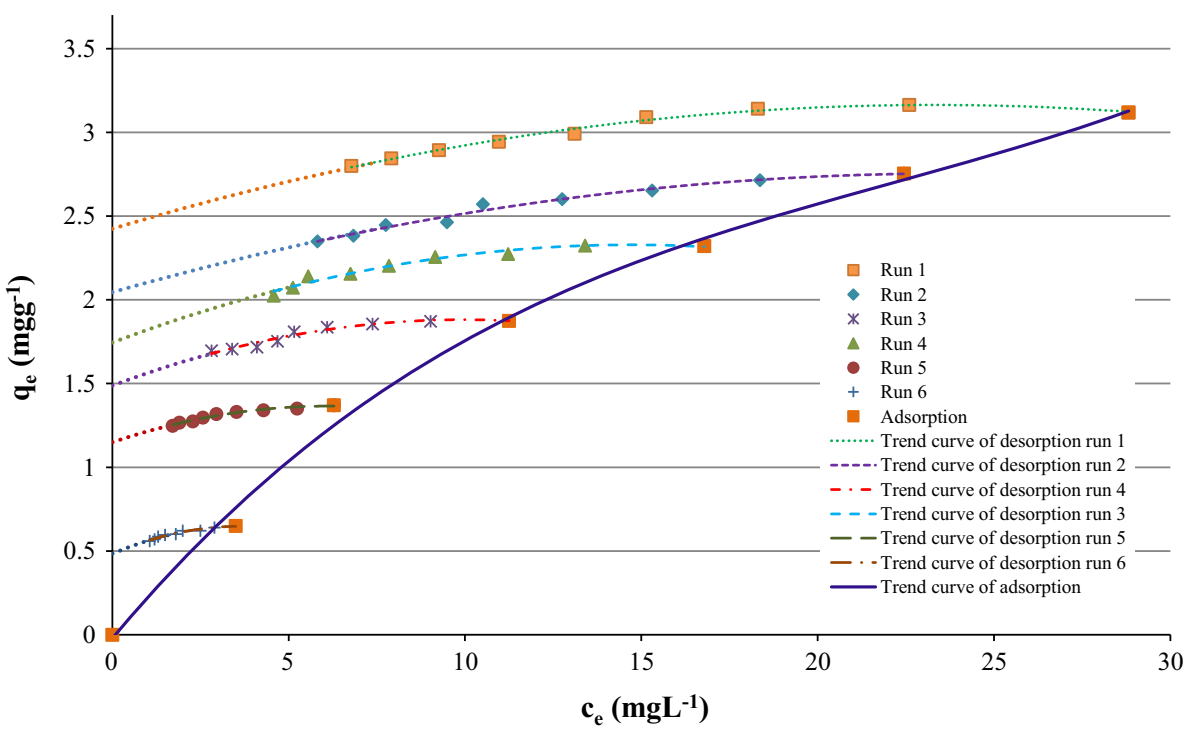


Table 3 Thermodynamic indices of irreversibility TII, parameters of the modelled trend curves for desorption isotherms and irreversibly ratios of the adsorbed dye for the bentonite sample

\begin{tabular}{llllllll}
\hline Desorption experiment & $q_{e}^{(0)}\left(\mathrm{mg} \mathrm{g}^{-1}\right)$ & TII (-) & $\begin{array}{l}a_{0}\left(\mathrm{mg} \mathrm{g}^{-1}\right) \\
y=a_{0}+a_{1} x+a_{2} x^{2}\end{array}$ & $\begin{array}{c}a_{1}\left(\mathrm{Lg}^{-1}\right) \\
a_{2}\left(\mathrm{mg} \mathrm{g}^{-1} \mathrm{~L}^{2}\right)\end{array}$ & $R^{2}(-)$ & $a_{0} / q_{e}^{(0)}(\%)$ \\
\hline Run 1 & 3.11 & 0.88 & 2.42 & 0.0635 & -0.0014 & 0.98 \\
Run 2 & 2.75 & 0.75 & 2.04 & 0.0595 & -0.0012 & 0.98 \\
Run 3 & 2.32 & 0.75 & 1.74 & 0.0793 & -0.0027 & 0.96 \\
Run 4 & 1.87 & 0.83 & 1.48 & 0.0790 & -0.004 & 74 \\
Run 5 & 1.37 & 0.92 & 1.14 & 0.0707 & -0.0058 & 0.95 \\
Run 6 & 0.65 & 0.65 & 0.48 & 0.0889 & -0.0121 & 79 & 83 \\
\hline
\end{tabular}

Fig. 7 Different phases (from $n=1$ to $n=6$ ) of the FB desorption isotherms (a) and the partitioning coefficient $\mathrm{K}_{\mathrm{d}}$ versus the number of desorption steps (b)

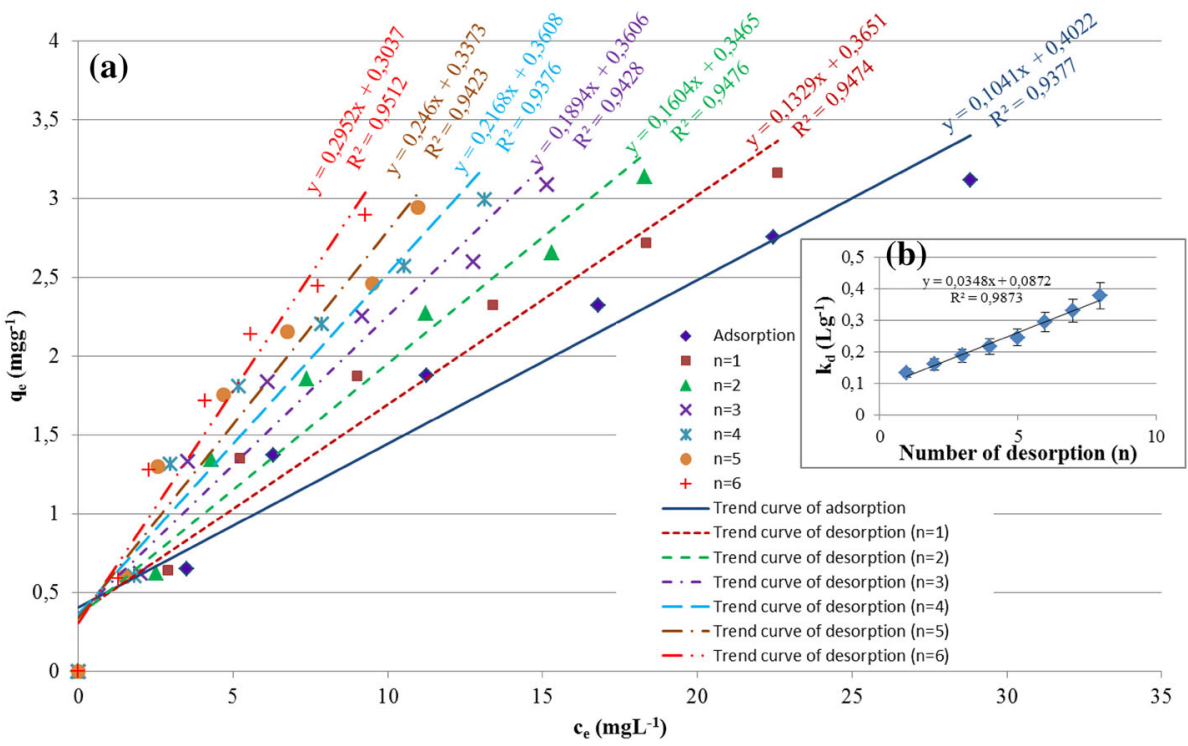

isotherms obtained for each of the $n$ dilution steps were fitted using the following linear desorption model:

$q_{e}^{(n)}=k_{d}^{(n)} c_{e}^{(n)}$

where $k_{\mathrm{d}}\left(\mathrm{L} \mathrm{g} \mathrm{g}^{-1}\right)$ represents the partitioning coefficient. All the experimental data were projected on a straight line (Fig. 7). In addition, the partitioning distribution coefficients $\left(k_{\mathrm{d}}\right)$ obtained were plotted as a function of $\mathrm{n}$ (Fig. 7b). However, because the regression curve is still linear, it was not possible to determine the maximum desorption partitioning coefficient $K_{\mathrm{m}}\left(\mathrm{L} \mathrm{g}^{-1}\right)$, which may be theoretically determined for an infinite number of desorption steps (Gebremariam et al. 2012). It is likely that additional experimental desorption procedures must be conducted to observe this behaviour.

This latter process is referred to as the hysteresis phenomenon of desorption, which is similar to the phenomenon described in the literature related to the desorption of dye tracers (e.g. Morris et al. 2008; Zhou and Wang 2010) and pesticides (Abdullah et al. 2001; Huang et al. 2003; Madrigal-Monarrez 2004) in sandy and bentonite soils.
The extrapolation of trend curves denoted by the dotted lines in Fig. 6 present ratios of FB varying from 73 to $83 \%$ that were irreversibly retained for the bentonite sample. They are approximately $10 \%$ higher than the ratios found for the bentonite sample extracted from Gafsa (Berez et al. 2014). This is consistent with the calculated thermodynamic index of irreversibility (Sander et al. 2005) that varied in the present study from 0.65 to 0.92 , indicating that FB adsorption was partially reversible (Table 3). The thermodynamic study on adsorption showed that FB adsorption on the natural bentonite involved an exergonic, spontaneous reaction and a physical process (Berez 2015).

\section{Column experiments}

\section{Hydrodynamic behaviour of the clay-sand mixture}

Figure 8 shows the measured breakthrough curves of the non-reactive tracer (fluorescein) for the experimental series, where the mass ratios of clay within the clay/sand mixture varied from 0 to $30 \%$. To compare the 


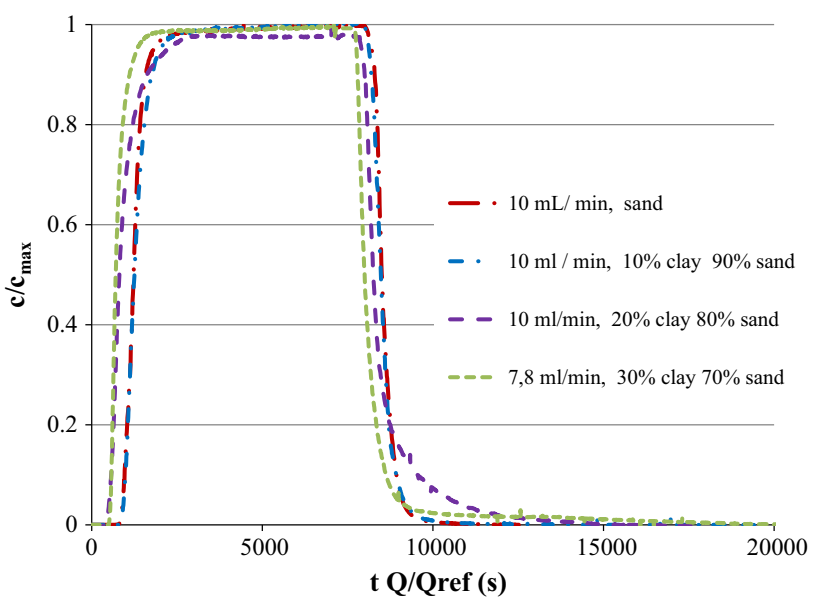

Fig. 8 Concentration breakthrough curves of the non-reactive tracer (Fluorescein) measured at the column outlet for 0, 10, 20 and $30 \%$ mass ratios of clay as a function of scaled time. $Q$ and $Q_{\text {ref }}$ denote the flow rate of the experiment and a reference flow rate of

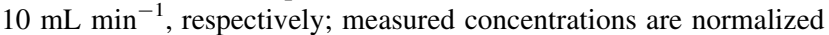
to the fixed concentration of the tracer pulse $c_{\max }$ of $9 \mathrm{mgL}^{-1}$

experiments, tracer concentrations measured in the column outlet (shown here and below) are normalized to the initial concentration of the tracer pulse $\left(c_{\max }\right)$, whereas the time $\mathrm{t}$ is multiplied by the ratio of the measured flow rate $\mathrm{Q}$ of the individual experiment to the reference flow rate $Q_{\text {ref }}$ of $10 \mathrm{~mL} \mathrm{~min}^{-1}$. Note that in all the tracer experiments, a fixed volume of $1200 \mathrm{~mL}$ of tracer was injected into the entrance section of the column.

In all the tracer experiments, nearly $100 \%$ of the injected non-reactive tracer was recovered (Table 4). However, with increasing mass ratios of clay, the measured breakthrough curves are characterized by a steep increase in concentration levels during earlier periods compared to those observed in the sand filling without clay and a marked concentration tailing (Fig. 8). The same behaviours were found with decreasing tracer pulse concentration values. This is typically the behaviour of advectivedispersive mass transport in a heterogeneous porous medium when transport occurs at a small scale and when permeability distributions tend to be bimodal. In such a case, the description of mass transport using the Fickian dispersion concept is inaccurate; the simplest approach may involve assuming that there is mobile and an immobile zone based on the fact that the mass flux between the two zones is proportional to the difference in concentration (Herr et al. 1989). This is the so-called dual porosity or double porosity concept. As noted by Herr et al. (1989), the flow rate also affects the arrival time of the tracer at the column outlet (Fig. 9). In our study, the impact of mass flux between mobile and immobile zones on tracer breakthrough levels thus decreases with the flow rate. For the given mass fraction of $20 \%$ clay, at high flow rates, the

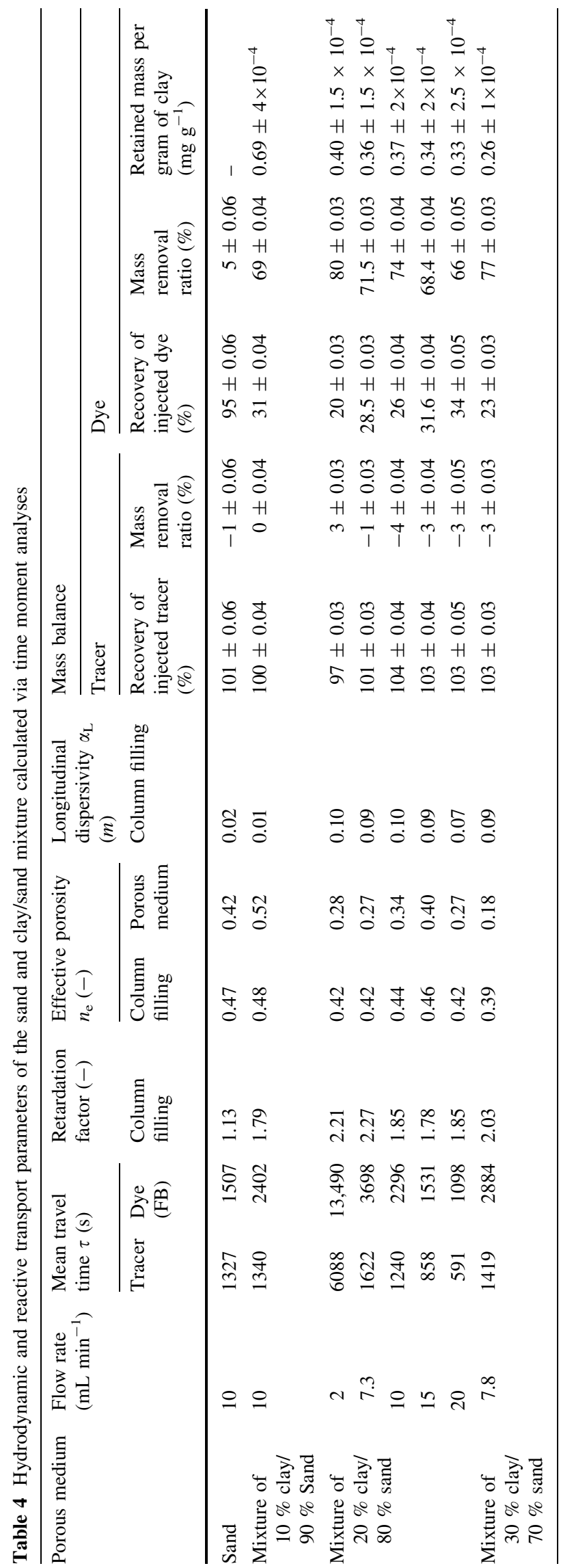




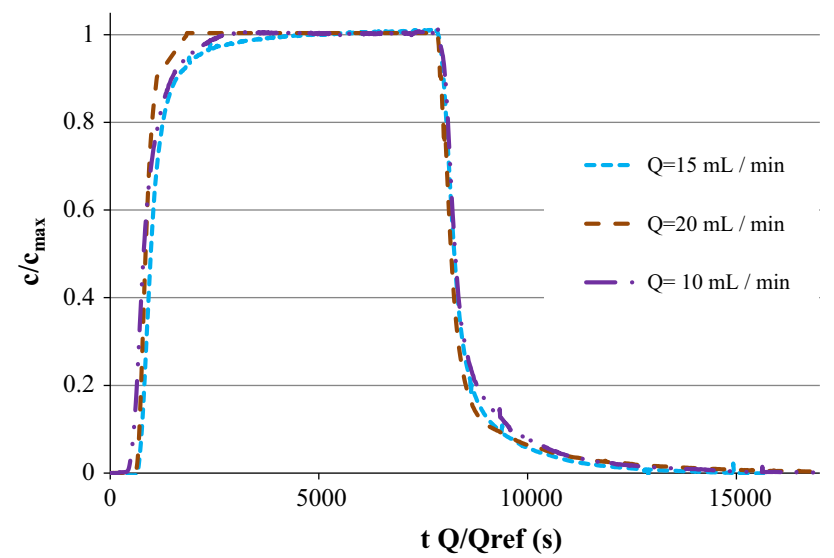

Fig. 9 Concentration breakthrough curves of the non-reactive tracer (Fluorescein) measured at the column outlet for different flow rates in the case of a $20 \%$ mass ratio of clay as a function of scaled time

tracer breakthrough is earlier and steeper than that of low flow rates. It appears that the mass exchange between mobile and immobile zones is controlled by molecular diffusion and thus do not depend on the flow rate. This result may explain why advective mass transport processes in the mobile zone becomes more important when the flow rate increases.

Based on our time moment analysis of the breakthrough curves obtained through the non-reactive tracer experiments, two hydrodynamic parameters of the column filling and of the porous medium were determined: effective porosity and longitudinal dispersivity (Table 4). Note that the effective porosity of the studied porous medium, i.e. sand and a mixture of clay and sand, was obtained from the derived specific mean travel time using Eqs. 22 and 23. In the case of the homogeneous sand, based on the volume of the outlet filter, outlet chamber and tubing, the effective porosity was determined as 0.42 . This corresponds to the experimental values obtained through former column studies (e.g. Bohy et al. 2006). With increasing mass ratios of clay, the effective porosity of the clay/sand mixture decreased (with the exception of the $10 \%$ clay mixture) from 0.42 (sand) to approximately 0.18 . This is principally attributable to the bimodal nature of the porous medium, and this underscores the observation that the higher the mass fraction of clay, the earlier the breakthrough of tracers at the outlet will occur. Another reason for these lower effective porosities is given by literature data on the effective porosities of clayey soils in the order of 0.05 and 0.1 (Castany and Margat 1974). The equivalent value of the longitudinal dispersivity for the various column fillings (porous media, outlet filter and outlet chamber) varied between $0.02 \mathrm{~m}$ for the homogeneous porous medium (sand) and up to $0.1 \mathrm{~m}$ in the case of the clay/sand mixture. Note that for the sand filling, the obtained dispersivity was approximately 20 times higher than its physical value quantified through specific dispersion experiments (Benremita and Schäfer 2003). This is principally due to the mixing effect of the column outlet chamber.

\section{Adsorption of FB on the clay-sand mixture}

Figure 10 shows the results of a first series of reactive transport experiments with FB (dye) involving the use of clay-sand mixtures with $0,10,20$ and $30 \%$ mass fractions of clay and conducted at a flow rate of approximately $10 \mathrm{~mL} \mathrm{~min}{ }^{-1}$. The concentration breakthrough curves of FB measured at the column outlet are compared to those obtained for the non-reactive tracer fluorescein.

The concentration breakthrough curve in the column filling without any clay serves as a reference. The homogeneous medium-sized sand is inert and does not fix any dye mass (Fig. 10). The measured breakthrough curve of FB is similar to that observed for fluorescein. For the nonreactive tracer fluorescein, the recovery rate of the solute at the column outlet was close to $100 \%$ (Table 4).

The presence of clay within the column filling strongly modified the breakthrough of FB at the column outlet. Compared to the non-reactive tracer, the concentration breakthrough was delayed and the measured maximum concentration of FB did not exceed $37 \%$ of the injected concentration. This clearly reveals high levels of FB adsorption into the clay minerals examined. The higher the mass fraction of clay within the clay-sand mixture, the lower the maximum concentration of FB measured at the outlet and the higher the mass removal ratio (Fig. 11; Table 4).

The reactive mass transfer of FB from the liquid phase to the solid phase results in an increase in the overall mean travel time of FB. For the homogeneous sand, the recovery of injected dye was approximately $95 \%$ and the retardation factor was quantified to 1.13 . This indicates that FB only adsorbs slightly into the solid matrix (Table 4) due to the low fraction of organic matter in the sand. However, for the soil filling with a mixture of clay and sand, very little dye was recovered (varying between 20 and $34 \%$ ), and the FB retardation factor was significantly higher than that found in the sand (varying between 1.78 and 2.21).

The influence of the flow rate on the adsorption of FB on the clay minerals at a fixed mass fraction of $20 \%$ clay 
Fig. 10 Concentration breakthrough curves of the nonreactive (Fluorescein) and reactive tracer (Foron Bleu (FB)) measured at the column outlet for different mass ratios of clay as a function of scaled time at a given flow rate of approximately $10 \mathrm{~mL} \mathrm{~min}{ }^{-1}$. $\left(c_{\text {max }, \text { dye }}=50 \mathrm{mg} \mathrm{L}^{-1}\right.$; $c_{\text {max }}$ tracer $=9 \mathrm{mgL}^{-1}$ )

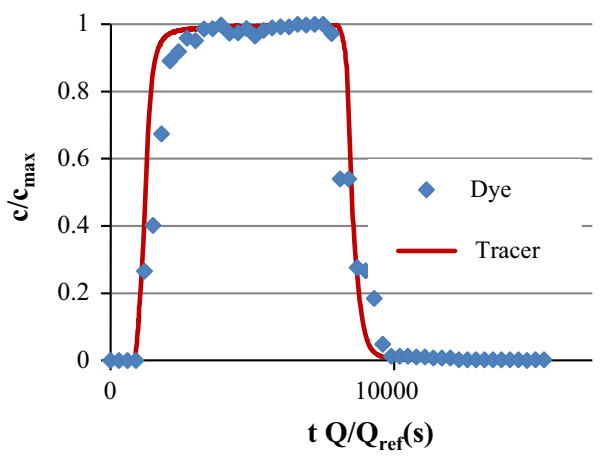

( $0 \%$ clay : homogeneous sand filling)

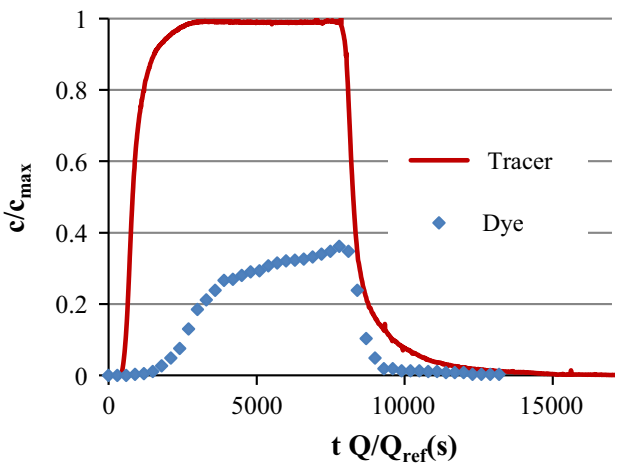

(20\% clay)

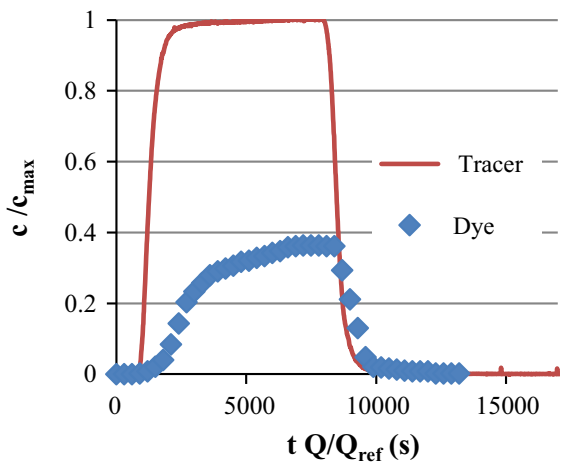

(10\% clay)

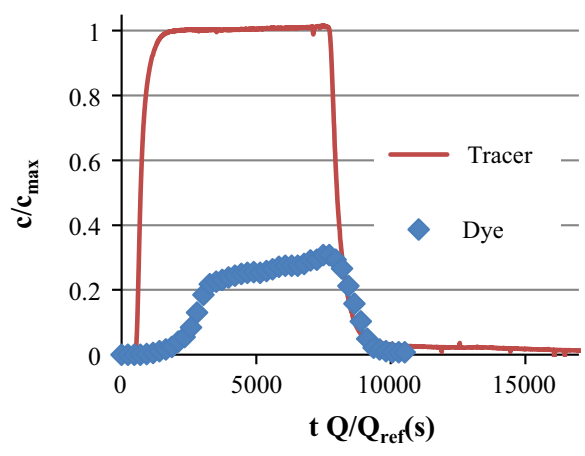

(30\% clay)

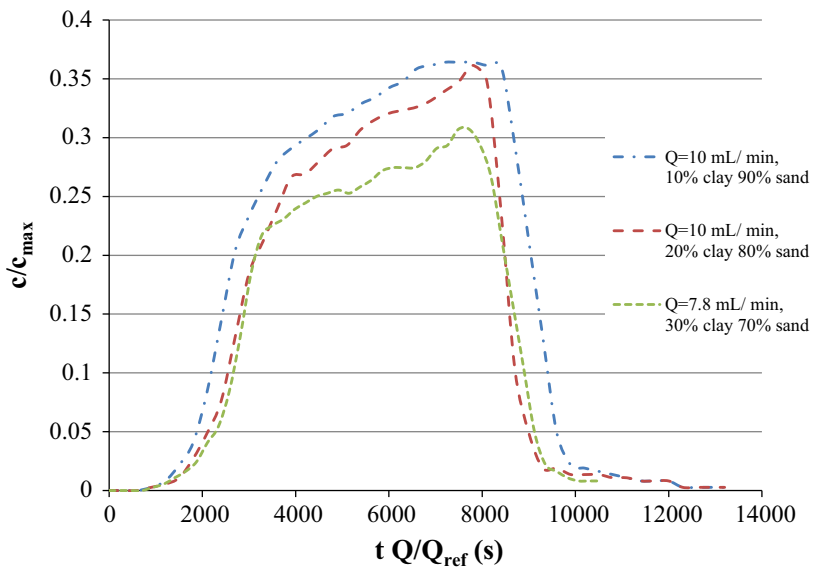

Fig. 11 Concentration breakthrough curves of the reactive tracer (FB) measured at the column outlet for 10, 20 and $30 \%$ mass ratios of clay as a function of scaled time

within the clay-sand mixture is shown in Fig. 12. The lower the flow rate was, the lower the maximum FB concentration and the higher the mean travel time of the solute became. A maximum removal ratio of $80 \%$ was thus

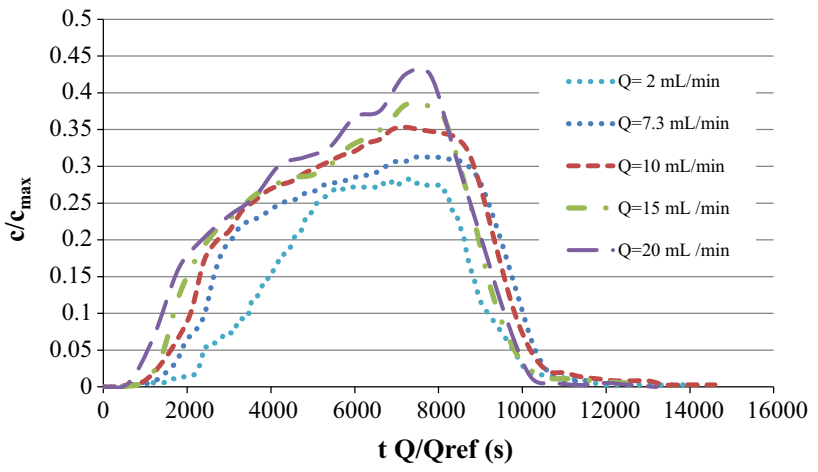

Fig. 12 Concentration breakthrough curves of the reactive tracer (FB) obtained for the clay-sand filling with a $20 \%$ mass fraction of clay using different flow rates as a function of scaled time

obtained for the lowest flow rate (Table 4). This can clearly be attributed to a reactive mass transfer of FB from a liquid to solid phase that becomes more significant for lower flow rates, i.e. lower flow rates result in longer travel times in the 11-cm-long reactive zone. In other words, overall mass transport is dominated by adsorption kinetics that are only 
(a)

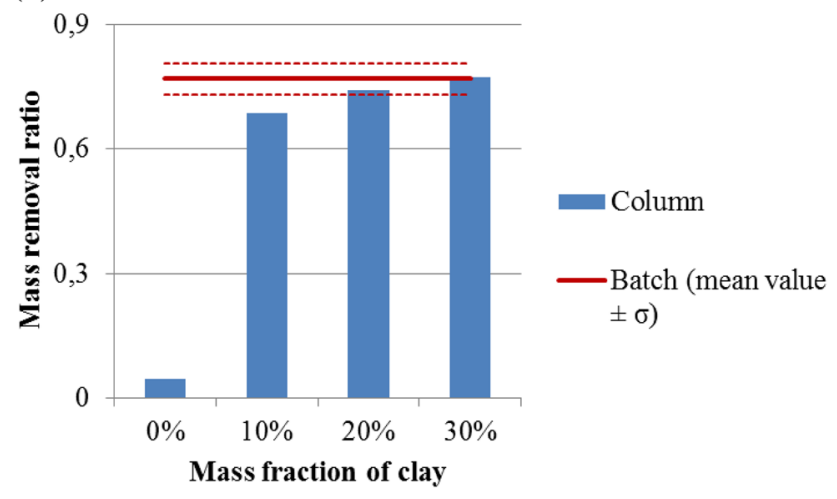

(b)

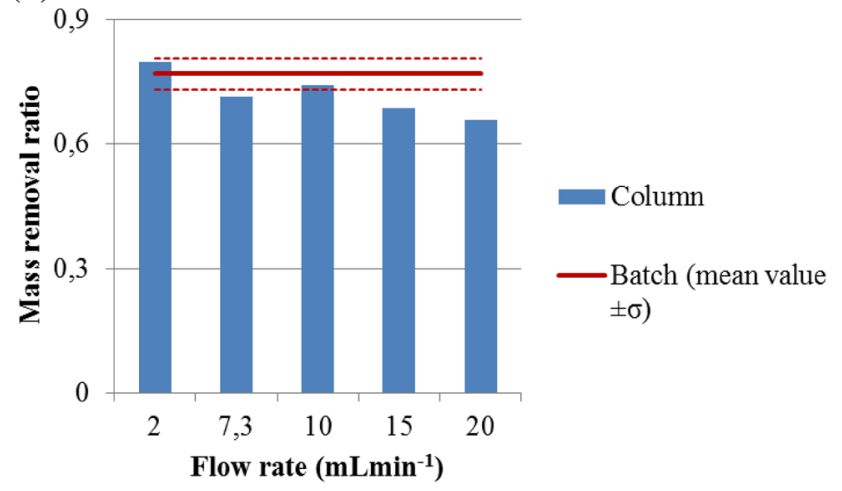

Fig. 13 Ratio of mass of FB retained on the clay-sand mixture in the column experiments compared to the average value obtained from the batch experiments as a function of a the mass fraction of clay at a given flow rate of $10 \mathrm{~mL} \mathrm{~min}{ }^{-1}$, and $\mathbf{b}$ the flow rate at a fixed mass fraction of $20 \%$ clay in the clay-sand filling

partly reversible. This has already been stated in our discussion of the batch reactor experiment results.

\section{Comparison of adsorptive FB removal processes under static and dynamic flow conditions}

The adsorption of organic compounds on clay minerals generally depends on the reactivity area involved, on the overall charge of the colloidal particles and on physicochemical conditions in particular. Indeed, from a phenomenological point of view, our study on the adsorption of the FB dye on clays under static and dynamic conditions should present the same results in accordance with adsorption kinetics unless mineral surface properties are altered.

Under the same physicochemical conditions, the adsorptive removal ratio will strictly depend on the flow rate of the dye solution used and on the mass ratio of fine adsorbent materials within the column filling. The results show that for a sufficiently long residence time of FB dye in a soil column, the ratio of irreversibly adsorbed FB molecules in a dynamic flow system is the same as under static no-flow conditions (Fig. 13). In addition, when the porous matrix contains a high mass fraction of clay ( $30 \%$ ), the removal rate of dissolved FB by the porous medium involved is the same as that observed in our batch experiments (see Table 4). However, in all the reactive tracer experiments, the masses of FB irreversibly adsorbed on the clay minerals are lower than those quantified in the batch experiments, that varied in the present study between $1.14 \mathrm{mg} \mathrm{g}^{-1}$ (run 5) and $2.42 \mathrm{mg} \mathrm{g}^{-1}$ (run 1) for initial dye concentrations in the liquid of 6.3 and $29 \mathrm{mg} \mathrm{L}^{-1}$, respectively (Table 3 ). For example, for the column filling with $20 \%$ mass fraction of clay, the retained FB mass per gram of clay varied slightly from approximately $0.33-0.4 \mathrm{mg} \mathrm{g}^{-1}$ (Table 4) which is six times lower than the maximum of FB mass that may be irreversibly adsorbed on the bentonite sample under static no-flow conditions (Table 3, Run1). This indicates that the adsorptive FB removal process in the soil column did not yet reach its upper limit.

\section{Conclusion}

Our adsorption studies show that the natural bentonite sample examined presents a strong capacity to irreversibly fix azoic FB dye due to its large specific surface area. This was observed under static continuous mixing conditions (batch reactor) between dissolved dye and an adsorbent and under dynamic flow conditions in well-defined column fillings containing a mixture of clay and sand. The contact time needed to achieve thermodynamic equilibrium between the adsorbate (FB) and adsorbent (clay) was quantified in our batch experiments. Furthermore, it can be concluded that the adsorption isotherm of FB on bentonite is Langmuir in type, and the FB molecules were removed from the liquid medium by physical adsorption.

Our experiments on the reactive transport of dissolved FB show that FB adsorption on natural clays heavily depends on the mass fraction of clay present in a column filling: the higher the mass fraction of clay, the higher the removal rate of FB from a liquid medium. A mass fraction increase is thus directly linked to an increase in the number of adsorption sites that may trap FB molecules. Moreover, it has been shown that the adsorptive 
irreversible removal ratio of dissolved FB also depends on the flow rate of an injected dye solution. Rather, the lower the flow rate becomes, the higher the ratio of mass removal will be. This is directly attributed to an increase in contact time between adsorbates and adsorbents that favours the achievement of a thermodynamic equilibrium between dissolved dye concentrations and dye masses adsorbed on a solid. Furthermore, it has been shown that the adsorptive FB removal process in the soil column did not yet reach its upper limit. It is likely that additional column experiments must be conducted at higher mass of injected dye to quantify the limit of mass retained per gram of clay under dynamic flow conditions. In addition, tracer experiments performed using the non-reactive tracer fluorescein clearly show that clay-sand mixtures are heterogeneously porous media with bimodal structures that can be hydrodynamically characterized by a double porosity model.

Overall, natural bentonite is less expensive and easier to manage than traditionally used adsorbents. Thus, it may serve as an efficient adsorbent for the treatment of wastewater in textile sectors. One major conclusion of this study is that the adsorptive removal of azoic dye on natural bentonite under dynamic flow conditions may be as efficient as continuous mixing reactors where thermodynamic conditions of equilibrium are achieved. Furthermore, from a practical point of view, to use natural clay minerals as adsorbents under dynamic flow conditions for the removal of dissolved azoic dye from water effluents has one disadvantage but also additional major advantages relative to the removal of azoic dyes using continuously stirred water-clay reactors. The use of percolation columns requires access to a rather permeable porous matrix to successfully seal the setup entrance section due to water head losses across the column filling. On the other hand, the dynamic flow configuration allows for the easy replacement of column fillings after wastewater treatment (like water filters used in traditional water treatment cycles). Furthermore, this technique presents reduced risks of the release of reversible portions of initially adsorbed dye mass as a column filling becomes charged with a pulse of dye mass that spurs a complete adsorption-desorption cycle.

Acknowledgments This work was performed within the framework of the PHC UTIQUE French-Tunisian project (12G21002) and was supported by the French Ministries of Foreign Affairs (MAE) and Education and Research (MESR) and by the Tunisian Ministry of Higher Education and Scientific Research.

\section{References}

Abdel Ghafar HH, Ali GA, Fouad OA, Makhlouf SA (2015) Enhancement of adsorption efficiency of methylene blue on Co3O4/SiO2 nanocomposite. Desalination Water Treat 53:2980-2989

Abdullah AR, Sinnakkannu S, Tahir NM (2001) Adsorption, desorption, and mobility of metsulfuron methyl in Malaysian agricultural soils. Bull Environ Contam Toxicol 71:655-661

Aris R (1958) On the dispersion of linear kinematic waves. Proc R Soc London Ser A 245:268-277

Auta M, Hameed BH (2014) Chitosan-bentonite composite as highly effective and low-cost adsorbent for batch and fixed-bed adsorption of methylene blue. Chem Eng J 237:352-361

Barka N, Nounah A, Assabbane A, Aît-Ichou Y (2006) Évaluation du pouvoir adsorbant du phosphate naturel dans le traitement des rejets textiles : Comparaison avec le charbon actif. Covaphos ii 4:195-203

Benguella B, Yacouta-Nour A (2009) Elimination des colorants acides en solution aqueuse par la bentonite et le kaolin. C R Chim 12:762-771

Benremita H (2002) Approche expérimentale et simulation numérique du transfert de solvants chlorés en aquifère alluvial contrôlé, Thèse, Université Louis Pasteur de Strasbourg, p 281

Benremita H, Schäfer G (2003) Transfert du trichloréthylène en milieu poreux à partir d'un panache de vapeurs. C R Mecanique 331:835-842

Berez A (2015) Dépollution par l'argile naturelle d'effluents teinturiers- Etude expérimentale et modélisation du processus d'adsorption/désorption en réacteur fermé et en colonne de percolation. Thèse de Doctorat, Université de Strasbourg

Berez A, Ayari F, Abidi N, Schäfer G, Trabelsi-Ayadi M (2014) Adsorption-desorption processes of azo dye on natural bentonite: batch experiments and modeling. Clay Miner 49:747-763

Bohy M (2003) Caractérisation de sources de pollution composées d'un mélange de solvants chlorés en aquifère alluvial- Expérimentations en laboratoire et sur site contrôlé associées à la simulation numérique. Thèse de doctorat, Université louis Pasteur, Strasbourg, p 170

Bohy M, Dridi L, Schäfer G, Razakarisoa O (2006) Transport of a mixture of chlorinated solvents vapors in the vadose zone of a sandy aquifer: experimental study and numerical modeling. Vadose Zone J 5:539-553

Calero M, Ronda A, Martın-Lara MA, Perez A, Blazquez G (2013) Chemical activation of olive tree pruning to remove lead (II) in batch system: factorial design for process optimization. Biomass Bioenergy 58:322-332

Calvo B, Canoira L, Morante F, Martinez-Bedia JM, Vinagre C, Garcia-Gonzalez J, Elsen J, Alcantara R (2009) Continuous elimination of $\mathrm{Pb}^{2+}, \mathrm{Cu}^{2+}, \mathrm{Zn}^{2+}, \mathrm{H}^{+}$and $\mathrm{NH}^{4+}$ from acidic waters by ionic exchange on natural zeolites. J Hazard Mater 166:619-627

Castany G, Margat J (1974) Dictionnaire Français d'Hydrogéologie. BRGM, Orléans

Cotel S, Schäfer G, Barthes V, Baussand P (2011) Effect of densitydriven advection on trichloroethylene vapor diffusion in a porous medium. Vadose Zone J 10:565-581

Depci T, Kul AR, Onal Y (2012) Competitive adsorption of lead and zinc from aqueous solution on activated carbon prepared from Van apple pulp: study in single- and multi-solute systems. Chem Eng J 200-202:224-236 
Dincer AR, Gunes Y, Karakaya N (2007) Coalbased bottom ash (CBBA) waste material as adsorbent for removal of textile dyes tuffs from aqueous solution. J Hazard Mater 141:529-535

Dodge Y, Rousson V (2004) Analyse de régression appliquée. DUNOD, Paris

Edelin F (1998) L'épuration physico-chimique des eaux. Edition Cebedoc, Liège

El Kbir L, Ouali MS, El Maleh S (1998) Epuration physico-chimique des rejets liquides de l'industrie textile (Zone industrielle d'El Jadida - Maroc). L'eau, l'industrie, les nuisances 214:54-60

Eren E, Afsin B (2007) Investigation of a basic dye adsorption from aqueous solution onto raw and pretreated sepiolite surfaces. Dyes Pigm 73:162-167

Gebremariam YS, Beutel WM, Flury M, Ames Harsh BJ, Avid Yonge RD (2012) Nonsingular adsorption/desorption of chlorpyrifos in soils and sediments: experimental results and modeling. Environ Sci Technol 46:869-875

Gerçel Ö, Gerçel HF, Koparal AS, Ögütveren ÜB (2008) Removal of disperse dye from aqueous solution by novel adsorbent prepared from biomass plant material. J Hazard Mater 160:668-674

Ghorbel-Abid I, Trabelsi-Ayadi M (2011) Competitive adsorption of heavy metals on local landfill clay. Arab J Chem. doi:10.1016/j. arabjc.2011.02.030

Herr M, Schäfer G, Spitz KH (1989) Experimental studies of mass transport in porous media with local heterogeneities. J Contam Hydrol 4:127-137

Huan X, Huiping Z, Pengfei L, Ying Y (2016) Preparation of high purity propane from liquefied petroleum gas in a fixed bed by removal of sulfur and butanes. Chem Eng J 284:224-232

Huang G, Li Q, Zhang X (2003) Adsorption and desorption of trazine by tree soils. Bull Environ Contam Toxicol 71:655-661

Jellali S, Benremita H, Muntzer P, Razakarisoa O, Schäfer G (2003) A large-scale experiment on mass transfer of trichlorethylene from the unsaturated zone of a sandy aquifer to its interfaces. J Contam Hydrol 60(1-2):31-53

Jiang W, Zengwei Y, Jun B, Li S (2010) Conserving water by optimizing production schedules in the dyeing industry. J Clean Prod 18:1696-1702

Langmuir I (1916) The constitution and fundamental properties of solid sand liquids. J Am Chem Soc 38:2221-2295

Langmuir I (1918) The adsorption of gases on plan surfaces of glass, mica and platinum. J Am Chem Soc 40:1361-1403

Madrigal-Monarrez I (2004) Rétention de pesticides dans les sols des dispositifs tampon enherbés et boisés; rôle des matie'res organiques. PhD Thesis, Institut National Agronomique ParisGrignon, Paris, France

Mlayah A, Jellali S (2015) Study of continuous lead removal from aqueous solutions by marble wastes: efficiencies and mechanisms. Int J Environ Sci Technol 12:2965-2978
Morris C, Mooney SJ, Young SD (2008) Sorption and desorption characteristics of the dye tracer, Brilliant Blue FCF, in sandy and clay soils. Geoderma 146:434-438

Palmieri G, Cennamo G, Sannia G (2005) Remazol Brilliant Blue R decolourisation by the fungus Pleurotus ostreatus and its oxidative enzymatic system. Enzyme Microb Technol 36:17-27

Qadeer R (2007) Adsorption behavior of ruthenium ions on activated charcoal from nirtic acid medium. J Colloid Interf Sci A Physicochem Eng Aspects 293:217-223

Rajabi M, Mirz B, Mahanpoor K, Mirjalili M, Najafi F, Moradi O, Sadegh H, Shahryari-ghoshekandi R, Asif M, Tyagi I, Agarwal S, Gupta VK (2016) Adsorption of malachite green from aqueous solution by carboxylate group functionalized multiwalled carbon nanotubes: determination of equilibrium and kinetics parameters. J Ind Eng Chem 34:130-138

Sadegh H, Shahryari-Ghoshekandi R, Tyagi I, Agarwal S, Gupta VK (2015) Kinetic and thermodynamic studies for alizarin removal from liquid phase using poly-2-hydroxyethyl methacrylate (PHEMA). J Mol Liq 207:21-27

Sadegh H, Zare K, Maazinejad B, Shahryari-ghoshekandi R, Tyagi I, Agarwal S, Gupta VK (2016) Synthesis of MWCNT-COOHCysteamine composite and its application for dye removal. J Mol Liq 215:221-228

Sander M, Lu Y, Pignatello JJ (2005) A thermodynamically based method to quantify true sorption hysteresis. J Environ Qual 34:1062-1072

Schäfer G (1991) Einfluß von Schichtenstrukturen und lokalen Einlagerungen auf die Längsdispersion in Porengrundwasserleitern. Mitteilungen des Instituts für Wasserbau, Heft 75, Universität Stuttgart, 154p., ISBN 3-921694-75-2

Shahryari-Ghoshekandi R, Sadegh H (2014) Kinetic study of the adsorption of synthetic dyes on graphene surfaces. Jordan J Chem 9:267-278

Sørensen T (1996) Textilkemi 3. Farvningog Trykning

Srinivasan A, Viraraghavan T (2010) Decolorization of dye wastewaters by biosorbents: a review. J Environ Manage 91:1915-1929

Wang Y, Wang W, Wanga A (2013) Efficient adsorption of methylene blue on an alginate-based nanocomposite hydrogel enhanced by organo-illite/smectite bentonite. Chem Eng J 228:132-139

Yaneva Z, Koumanova B (2006) Comparative modelling of monoand dinitrophenols sorption on yellow bentonite from aqueous solutions. J Colloid Interf Sci 293:303-311

Young-Chul L, Minkee C, Ji-Won Y, Hyun-Jae S (2015) Removal of malachite green (MG) from aqueous solutions by adsorption, precipitation, and alkaline fading using talc: kinetic, thermodynamic, and column feasibility studies. Desalination Water Treat 56:1918-1928 
Yu M, Zhao S, Wu H, Asuha S (2013) Efficient removal of Congo red by magnetically separable mesoporous $\mathrm{TiO} 2$ modified with $\gamma$ Fe2O3. J Porous Mat 20:1353-1360

Zare K, Sadegh H, Shahryari-ghoshekandi R, Maazinejad B, Ali V, Tyagi I, Agarwal S, Gupta VK (2015) Enhanced removal of toxic Congo red dye using multi walled carbon nanotubes: kinetic, equilibrium studies and its comparison with other adsorbents. J Mol Liq 212:266-271

Zhou Q, Wang M (2010) Adsorption-desorption characteristics and pollution behavior of reactive $\mathrm{X}-3 \mathrm{~B}$ red dye in four Chinese typical soils. J. Soil Sediments 10:1324-1334 